\title{
Castelvecchio and Castiglione del Lago: Two new Italian iron meteorites ${ }^{\star}$
}

\author{
V. Moggi Cecchi ${ }^{1}$, G. Pratesi ${ }^{2}$,a, S. Caporali ${ }^{3}$, C.D.K. Herd ${ }^{4}$, and G. Chen ${ }^{4}$ \\ 1 Museo di Storia Naturale, Università degli Studi di Firenze, Via La Pira 4, 50121 Firenze, Italy \\ 2 Dipartimento di Scienze della Terra, Università degli Studi di Firenze, Via La Pira 4, 50121 Firenze, Italy \\ 3 Dipartimento di Ingegneria Industriale, Università degli Studi di Firenze, Via di S. Marta 3, 50139 Firenze, Italy \\ 4 Department of Earth and Atmospheric Sciences, University of Alberta, 1-26 Earth Sciences Building, Edmonton, AB, T6G \\ 2E3, Canada
}

Received: 13 July 2017

Published online: 23 August 2017 - C Società Italiana di Fisica / Springer-Verlag 2017

\begin{abstract}
Until 2016 only 38 Italian meteorites have been classified and published on the Meteoritical Bulletin Database. Among these, only 4 were irons. We here report the results of the analyses performed on two iron meteorites recovered in Italy. The first one, Castiglione del Lago, weighing $667 \mathrm{~g}$, was recovered in 1970. The textural features observed by means of both optical microscope and SEM, as well as SEM-EDX and ICP-MS analyses, allowed to classify it as IAB-MG iron. The second one, named Castelvecchio, has been recovered at Lignana, near Pontito, in August 2015. In the same locality a fireball was witnessed on October 23, 1986, by Mario Goiorani, a meteorite collector. The main mass, weighing $49.5 \mathrm{~g}$, was recovered inside a hollow. A chip, observed with both optical metallographic microscope and SEM, displayed no kamacite lamellae at the centimetric scale, suggesting a classification as IIAB iron. This classification was confirmed by ICP-MS analyses. Both meteorites have been approved by the Meteoritical Society in 2016 and published in the on-line Meteoritical Bulletin Database (https://www.lpi.usra.edu/meteor).
\end{abstract}

\section{Introduction}

Italian meteorites are pretty rare due to the peculiar geographic and geomorphologic features of the Italian landscape, characterized by a predominance, in the central and southern part of the country, of mountains and hills, while large plain areas, suitable for meteorite recovery, are limited to the northern part (namely the Padana plain). Moreover, central and southern Italy extend longitudinally for no more than $300 \mathrm{~km}$ and this fact limits dramatically the opportunities to find a meteorite potentially associated to a big fireball, since there is a high probability for it to fall in the sea. Therefore, during two thousand years of meteor witnessing and meteorite recovery only 38 Italian meteorites, both finds and falls, have been recovered and officially approved by the Meteoritical Society and therefore published on the Meteoritical Bulletin Database. Among these, only 4 are irons and 2 are stony-irons. We report here the results of the analyses performed on two irony blocks recently recovered in Italy that confirmed their meteoritical origin. The first one is an iron recovered in 1970 near Castiglione del Lago (Perugia, Umbria) by a peasant while ploughing his field. The peasant preserved the sample for many years in his home considering it just a curiosity, until he read, in 2007, an interview of Matteo Chinellato, an Italian meteorite collector, who invited people to send him potential meteorites for analysis. Chinellato received the main mass, cut a slice and sent it to the Museo di Scienze Planetarie della Provincia di Prato and to the Museo di Storia Naturale dell'Università di Firenze for analysis. The main mass, weighing $667 \mathrm{~g}$, has a severely rusted outer surface and has been cut on one side to get the type specimen, weighing $27.2 \mathrm{~g}$, which is currently on deposit at the Museo di Scienze Planetarie della Provincia di Prato (fig. 1). The second meteorite, named Castelvecchio, has been recovered at Lignana, near Pontito, in the mountains over Pescia (Pistoia, Tuscany) on August 2015. In the same locality, near the Madonna del Soccorso church, a fireball was witnessed on October 23, 1986, at 4:13 a.m. by Mario Goiorani, a meteorite collector, who heard a loud hiss and saw a huge fireball moving eastward. In August 2015 a lumberjack was appointed by Goiorani to explore the area with a metal detector and a GPS, in order to check the presence of metallic objects. The man found several bomb splinters and a small, rounded,

\footnotetext{
* Contribution to the Focus Point on "Highlights of Planetary Science in Italy" edited by P. Cerroni, E. Dotto, P. Paolicchi.

a e-mail: giovanni.pratesi@unifi.it
} 


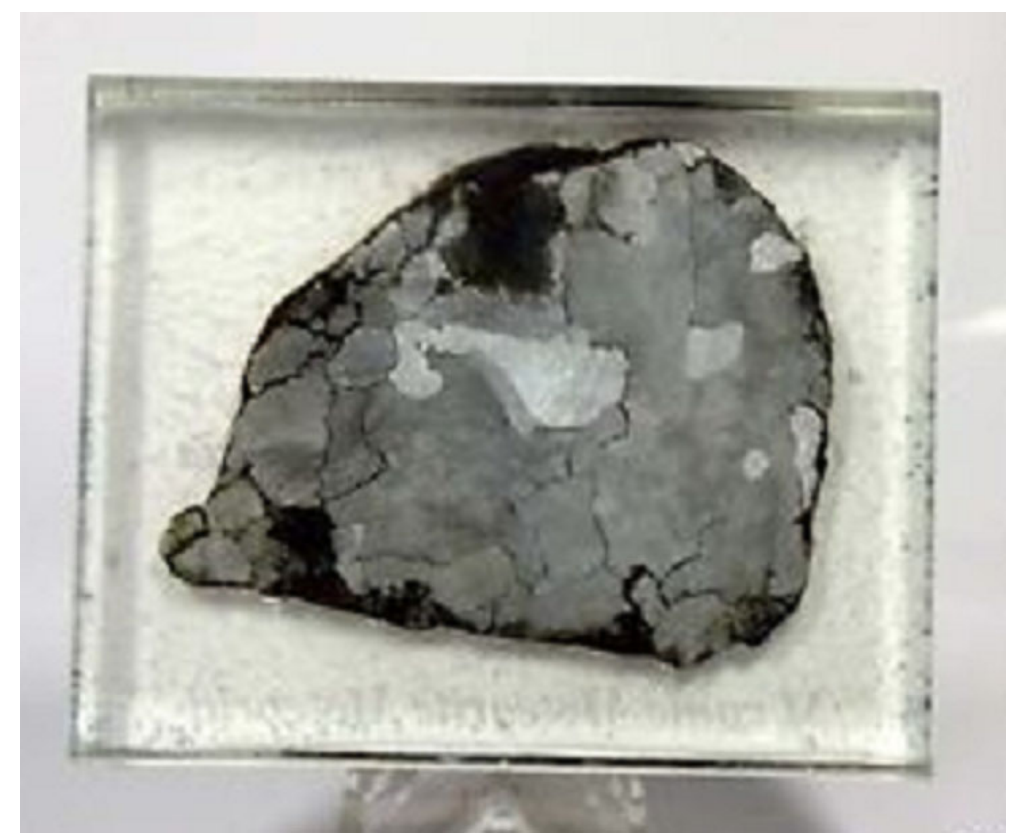

Fig. 1. Image of the type specimen of the Castiglione del Lago meteorite.

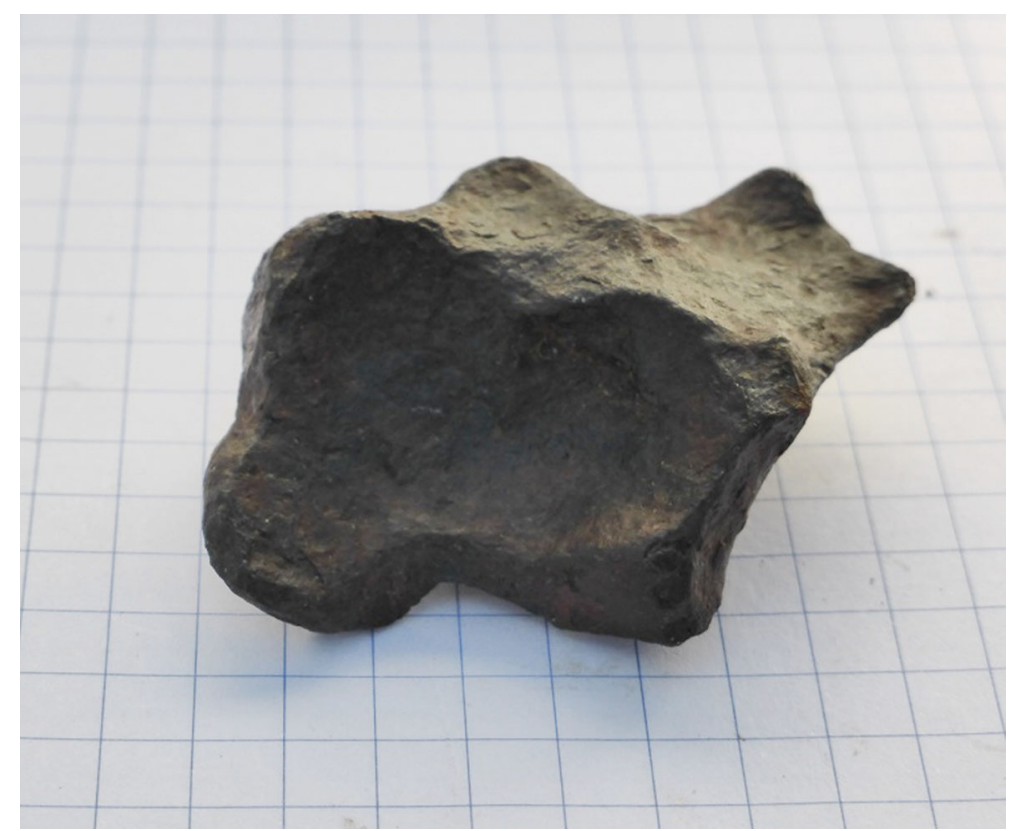

Fig. 2. Image of the main mass of the Castelvecchio meteorite.

metallic sample completely covered by rust. The coordinates of the find are the following: $43^{\circ} 59^{\prime} 05^{\prime \prime} \mathrm{N}, 10^{\circ} 43^{\prime} 21^{\prime \prime} \mathrm{E}$, height $810 \mathrm{~m}$ s.l.m.. The main mass, weighing $37 \mathrm{~g}$ (fig. 2), was recovered inside a hollow, around $10 \mathrm{~cm}$ under the soil surface and is currently on deposit at the Gruppo Autonomo Ricerche Scientifiche of Pescia, Pistoia. An $11 \mathrm{~g}$ sample and a polished section are on deposit at the Museo di Storia Naturale dell'Università di Firenze (inventory number RI-3280).

\section{Methods}

Optical analyses have been performed at the Department of Earth Sciences of the University of Florence by means of a Zeiss Axioplan II optical microscope equipped with a Zeiss Axiocam camera. Scanning electron microscope images and analyses have been performed both at the Department of Chemistry of the University of Florence by means 


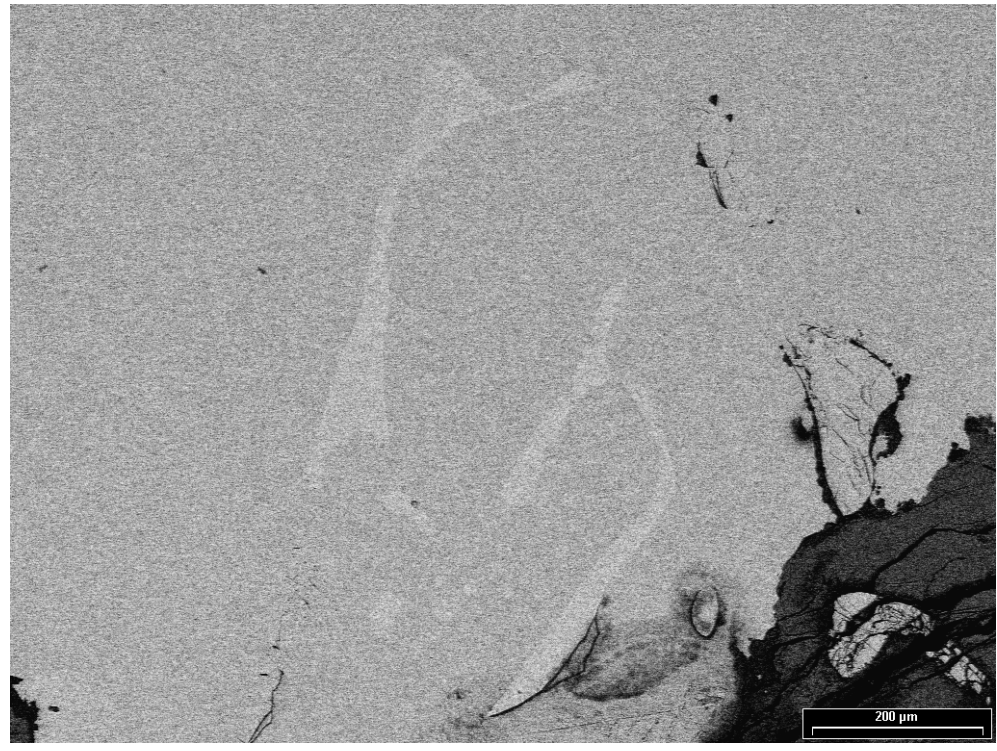

Fig. 3. SEM-BSE image of a polished section of Castiglione del Lago meteorite; dark grey is kamacite; light grey is taenite.

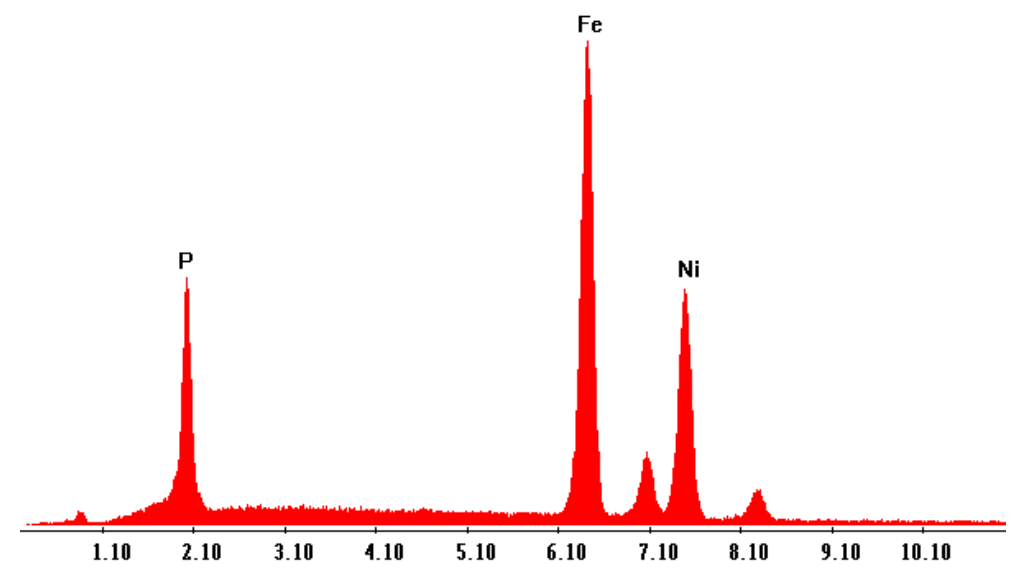

Fig. 4. SEM-EDS X-ray spot analysis of a schreibersite grain in Castiglione del Lago meteorite; P, Fe and Ni K lines are clearly visible.

of a Hitachi SEM equipped with a NORAN System-6 software and at the MEMA laboratories of the University of Firenze by means of a Zeiss EVO MA15 equipped with OXFORD INCA 250 microanalysis. ICP-MS analyses have been performed at the Department of Earth and Atmospheric Sciences, University of Alberta, Canada, laboratories by means of a $\mathrm{Nu}$ Plasma $^{\text {TM }}$ multi-collector inductively coupled plasma mass spectrometer (MC-ICP-MS).

\section{Experimental results}

\section{Castiglione del Lago}

A small chip of the meteorite was cut from the type specimen, cast in polyester resin, mirror-polished, and observed with an optical metallographic microscope in reflected light. Although silicate inclusions are visible on the cut and etched type specimen, the $1 \times 1 \mathrm{~cm}$ polished section examined does not contain silicates. Metal is formed by coarsegrained ( $\sim 4 \mathrm{~mm}$ width) equigranular kamacite grains with $120^{\circ}$ grain boundaries, inside which Neumann lines are visible. Taenite is rare. Scattered schreibersite laths, up to 100 microns in width and to $1 \mathrm{~mm}$ in length, can be observed within some kamacite grains and at grain boundaries, frequently surrounded by iron oxides. SEM-BSE images and analyses confirmed the presence of two Fe-Ni metal alloys (kamacite and taenite) as well as of schreibersite (figs. 3 and 4). SEM-EDX spot analyses, provided the following results (all in wt.\%): schreibersite $\mathrm{Fe}_{47.0 \pm 0.3} \mathrm{Ni}_{37.5 \pm 0.4} \mathrm{P}_{15.5 \pm 0.2}$ $(N=5)$; taenite $\mathrm{Fe}_{75.4 \pm 0.5} \mathrm{Ni}_{24.6 \pm 0.2}(N=5)$; kamacite $\mathrm{Fe}_{93.5 \pm 0.6} \mathrm{Ni}_{6.5 \pm 0.2}(N=7)$. A detailed bulk analysis obtained 


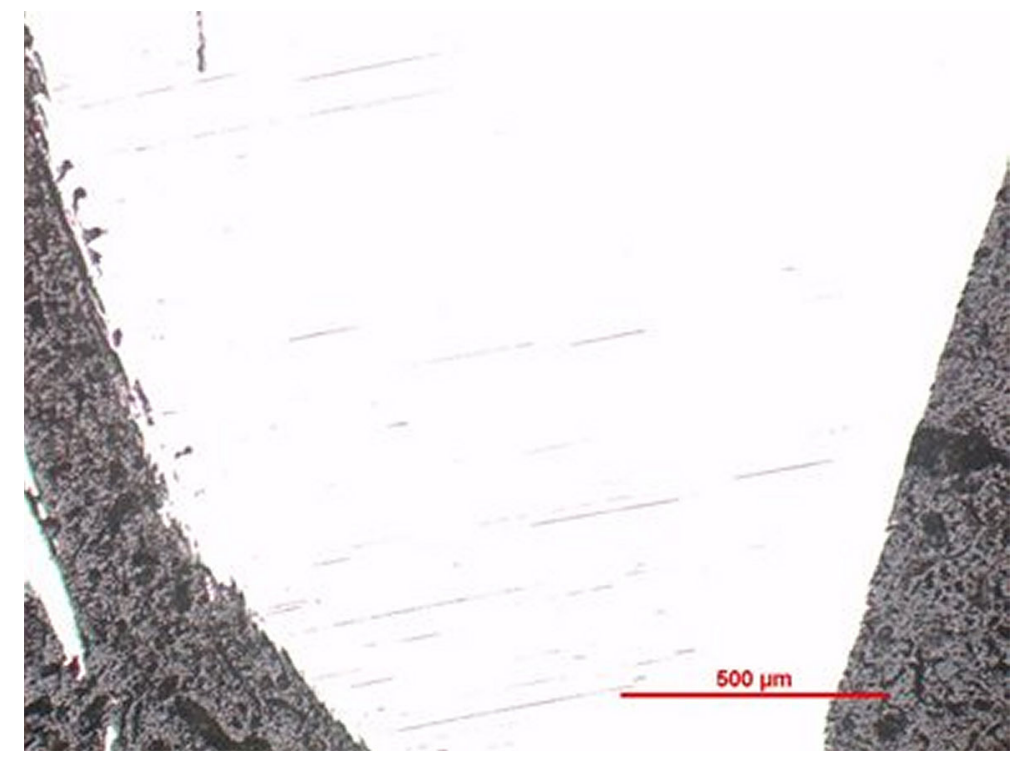

Fig. 5. Optical microscopy image of a polished section of Castelvecchio meteorite; grey areas are iron oxides; silver areas are kamacite.

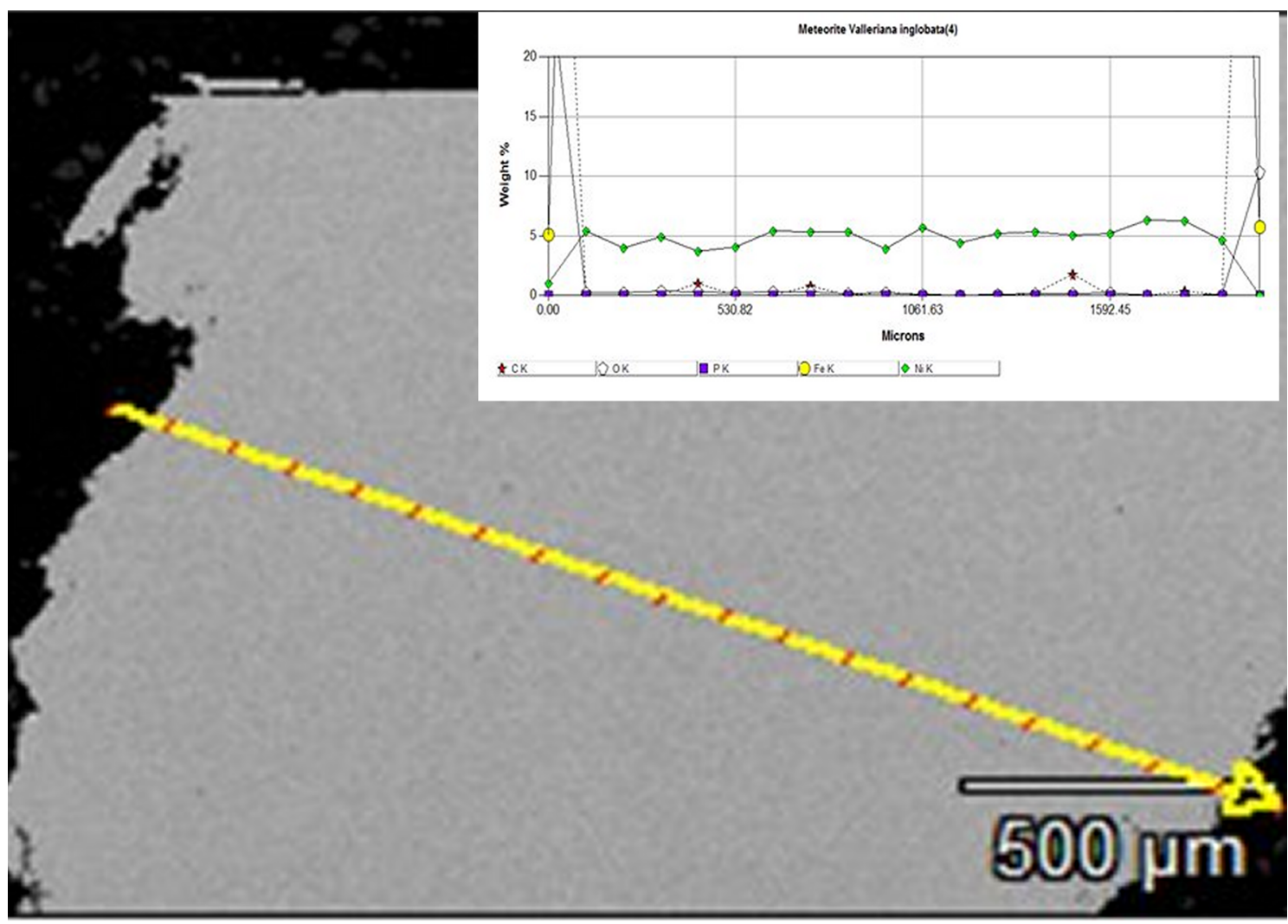

Fig. 6. SEM-BSE image of a polished section of Castelvecchio meteorite displaying a line transect across the entire section; in the top right corner the analytical results in wt.\% for $\mathrm{Fe}, \mathrm{Ni}, \mathrm{C}$ and $\mathrm{P}$ plotted against the distance in microns from one border to the other; the analyses are referred to the red spots along the yellow line in the main frame.

by ICP-MS, using North Chile iron meteorite as a calibration standard, provided the following results: Ni $=66.4$, $\mathrm{Co}=4.4($ both $\mathrm{mg} / \mathrm{g}) ; \mathrm{Cu}=151, \mathrm{Ga}=98.2, \mathrm{Ge}=414, \mathrm{~W}=1.4, \mathrm{Ir}=4.2, \mathrm{Pt}=8.1, \mathrm{Pd}=3.5, \mathrm{Ru}=7.0, \mathrm{Re}=0.3$, $\mathrm{Os}=1.4, \mathrm{Ag}=1.6, \mathrm{Sb}=0.5($ all $\mu \mathrm{g} / \mathrm{g})$. Textural data suggested a classification of the meteorite as Iron meteorite, IAB-complex, coarse octahedrite [1-3]. Major and trace elements composition is consistent with a classification as IAB-MG $[4,5]$. 


\section{Castelvecchio}

Even in this case the main mass was cut on one side to get the type specimen. The cut surface was etched and no Widmanstaetten pattern was visible on the etched surface. A small $(0.9 \times 1.2 \mathrm{~cm})$ chip of the meteorite was cut from the type specimen, cast in polyester resin, mirror-polished, and observed with an optical metallographic microscope in reflected light. The polished surface appears homogeneously formed by $\mathrm{Fe}, \mathrm{Ni}$ alloys, with no clearly distinguishable exsolution lamellae (fig. 5). SEM-BSE images confirmed this since no exsolution lamellae were detected in the exposed area. A SEM X-ray linescan performed across the entire section provided a homogeneous kamacitic composition with no appreciable variations (fig. 6). SEM-EDX spot analyses provided the following results (all in wt.\%): kamacite $\mathrm{Fe}_{95.1 \pm 0.5} \mathrm{Ni}_{4.5 \pm 0.5}(N=5)$ suggesting a structural classification as hexahedrite. Detailed bulk analyses obtained by solution ICP-MS using North Chile as an internal standard provided the following results: $\mathrm{Ni}=59.4, \mathrm{Co}=4.7$ (both $\mathrm{mg} / \mathrm{g}) ; \mathrm{Cu}=141, \mathrm{Ga}=55.5, \mathrm{Ge}=166, \mathrm{As}=4.1, \mathrm{~W}=1.3, \mathrm{Ir}=0.07, \mathrm{Pt}=3.2, \mathrm{Pd}=2.3, \mathrm{Ru}=3.0, \mathrm{Os}=5.2$, $\mathrm{Rh}=1.6, \mathrm{Ag}=0.6, \mathrm{Sb}=0.3($ all $\mu \mathrm{g} / \mathrm{g})$. These data are consistent with textural data and point to a classification as Iron meteorite, IIAB $[4,6]$.

\section{Conclusions}

These two new iron meteorites have been officially approved by the Nomenclature Committee of the Meteoritical Society under the names Castiglione del Lago and Castelvecchio in 2016 and published in the Meteoritical Bulletin Database on-line. They represent the fifth and the sixth iron meteorites ever discovered in Italy.

\section{References}

1. V.F.B. Buchwald, Handbook of Iron Meteorites, Vols. I-III (University of California Press, Berkely, 1975).

2. R. Hutchison, Meteorites: A Petrologic, Chemical and Isotopic Synthesis (Cambridge University Press, 2004).

3. H. Haack, T.J. McCoy, Iron and stony-iron meteorites, in Meteorites, Comets, and Planets, edited by A.M. Davis, Vol. 1 Treatise on Geochemistry, edited by H.D. Holland, K.K. Turekian (Elsevier-Pergamon, Oxford, 2007) Chapt. 1.12.

4. M. Grady, G. Pratesi, V. Moggi Cecchi, Atlas of Meteorites (Cambridge University Press, Cambridge, UK, 2014).

5. J.T. Wasson, G.W. Kallemeyn, Geochim. Cosmochim. Acta 66, 2445 (2002).

6. J.T. Wasson, H. Huber, D.J. Malvin, Geochim. Cosmochim. Acta 71, 760 (2006). 